\title{
Almotriptan Malate
}

National Cancer Institute

\section{Source}

National Cancer Institute. Almotriptan Malate. NCI Thesaurus. Code C61628.

The malate salt of almotriptan, a sulfonamide triptan with vasoconstrictor activity.

Almotriptan selectively binds to and activates serotonin 5-HT 1B and 1D receptors in the central nervous system (CNS), thereby causing cerebral blood vessel constriction. This may lead to pain relief from vascular headaches. Almotriptan may also relieve vascular headaches by preventing the release of vasoactive neuropeptides from perivascular trigeminal axons in the dura mater during a migraine, by reducing extravasation of plasma proteins, and by decreasing the release of other mediators of inflammation from the trigeminal nerve. 